\title{
Feasibility of an open-source algorithm for predicting sea surface temperature based on three multi-resolution data sources
}

\author{
Ranulfo Rodríguez-Sobreyra ${ }^{a}$, León Felipe Álvarez-Sánchez ${ }^{b}$, Francisco Flores-de-Santiago a ${ }^{\text {a }}$ \\ a Instituto de Ciencias del Mar y Limnología, Unidad Académica Procesos Oceánicos y Costeros, \\ Universidad Nacional Autónoma de México, Ciudad Universitaria, A.P. 70-305, Av. \\ Universidad 3000, Coyoacán, Cd. México 04510, Mexico. \\ b Instituto de Ciencias del Mar y Limnología, Unidad de Informática Marina, Universidad \\ Nacional Autónoma de México, Ciudad Universitaria, A.P. 70-305, Av. Universidad 3000, \\ Coyoacán, Cd. México 04510, Mexico. \\ *Corresponding autor \\ ORCID: 0000-0001-8813-0093 \\ Email: ffloresd@cmarl.unam.mx
}

\begin{abstract}
The quantification of sea surface temperature (SST) through space platforms has revolutionized how we obtain information at a global level. However, the main disadvantage of obtaining SST with satellite images consists of its inherent coarse spatial resolution. One solution could be the use of downscaling algorithms to create sequences of matrices at a higher resolution. We used the same SST data source from the MODIS-Aqua sensor at three spatial resolutions of $9 \mathrm{~km}, 4.5$ $\mathrm{km}$, and $1 \mathrm{~km}$ in the Gulf of California. Based on an open-source algorithm, the original SST images were downscaled to $4.5 \mathrm{~km}, 1 \mathrm{~km}, 500 \mathrm{~m}, 250 \mathrm{~m}$, and $125 \mathrm{~m}$ per pixel scales. Results indicate a strong linear relationship between the original SST-MODIS data and the modeled data for all spatial resolutions. This study demonstrates the feasibility of an open-source downscaling algorithm to enhance the spatial resolution of SST images in a marginal sea.
\end{abstract}

Keywords: Sub-pixel mapping; Super-resolution mapping; Downscaling; Gulf of California.

\section{Introduction}

Remote sensing has been an alternative approach to providing instantaneous data in large-scale studies. However, remote sensing data is generally not as accurate as in situ measurements and, depending on the sensor, could be limited to the surface layer of the sea (Jensen 2006). Despite this, the latter limitation is largely offset by the wide range of spatial and temporal resolutions offered by satellite observations. It is well known that in situ measurements have provided valuable and complementary means to validate satellite data (Mercado-Santana et al. 2017) and trends to improve the collected remote sensing data quality (Platt and Sathyendranath 2008), but in some inaccessible locations, in situ measurements are not feasible and therefore, space-borne observations are the only available data source (Kratzer et al. 2016). 
Remote sensing, geographic information systems, and modeling techniques have been used effectively in a myriad of studies regarding the monitoring of coastal and oceanic systems (Carrasco et al. 2016; Loisel et al. 2013). Among the variables that can be estimated from satellite data, sea surface temperature (SST) has been one of the most used in large-scale oceanographic studies (Barale et al. 2010). SST plays a key role in the energy exchange between the ocean and atmosphere interface (Devi et al. 2015). Therefore, SST is a fundamental variable to be able to analyze climate change (Knutson et al. 2010) and can be used as a conservative variable to assesses oceanographic phenomena such as the direction and forecast of tropical storms and hurricanes, detect areas with high turbulent kinetic energy (González -Silvera et al. 2004), evaluate dynamic biogeographic regions (Callejas-Jiménez et al. 2012), determine the influence of suspended terrestrial sediment from rivers (González-Silvera et al. 2006), and detect the possible impacts of the El Niño Southern Oscillation event. In addition, the spatial variability of the SST has been associated to a great extent with a strengthening of the density gradient that causes a decrease in the transport of nutrients through the pycnocline (Escalante et al. 2013), which have been quantified from thermal infrared bands since the early 1980s (Nielsen-Englyst et al. 2018).

Spatial resolution describes the number of pixels that can be used to generate an image from a data matrix and, therefore, indicates the amount of information that can be extracted from that image. In this sense, an image processed with a high spatial resolution generally provides more information and detail (Atkinson, 2005). Due to the above, the reconstruction of gap-free remote sensing data has been a critical issue for a long time and therefore, images generally rely on interpolation algorithms for their proper analysis (Fablet et al. 2018; Li and Heap 2008). In this sense, one alternative could be the use of downscaling techniques to process and obtain spatial information at a higher level. These techniques are based on the transformation of the original image data into matrix sequences with finer spatial resolutions (Wang and Shi 2014). In essence, downscaling treats pixels as a combination of surrounding pixels that affect a central one, based on their linear distance (Mokarrama and Hojati 2018). As such, spatial downscaling techniques estimate higher resolution indicator values from lower resolution fractional values (Ling et al. 2013) without the need for a priori spatial knowledge (Wang and Shi 2014).

Due to the inherent low spatial resolution of SST satellite data, in this study, we implemented and demonstrated the feasibility of an open-source downscaling technique along the Gulf of California (GC), Mexico. Therefore, the objective of this study was to test a downscaling algorithm with the same MODIS-Aqua data source at spatial resolutions of $9 \mathrm{~km}, 4.5 \mathrm{~km}$, and 1 $\mathrm{km}$. The specific objectives were: (i) to map and delineate SST data in scale reductions of 4.5 $\mathrm{km}, 1 \mathrm{~km}, 500 \mathrm{~m}, 250 \mathrm{~m}$, and $125 \mathrm{~m}$ per pixel, and (ii) to link the data from the MODIS-Aqua sensor with the results of SST algorithms in coastal and ocean waters using 1-by-1 and 3-by-3pixel sampling areas.

\section{Materials and methods}

\subsection{Study area.}

The GC is located on the northwest coast of Mexico (Fig. 1). It is an elongated marginal sea approximately $1000 \mathrm{~km}$ long with variable width $(\sim 90-200 \mathrm{~km})$, covering approximately 265900 
$\mathrm{km}^{2}$ including its marine and terrestrial area. Wind-driven processes, as well as their unique geomorphology, cause strong vertical currents that generate upwellings with high concentrations of dissolved nutrients towards the surface (Contreras-Catala et al. 2016). Therefore, the CG presents high primary productivity rates, even during strong events such as El Niño Southern Oscillation (Espinosa-Carreón and Escobedo-Urías 2017). The spatial distribution of primary productivity shows a latitudinal gradient for most of the year with the highest values in the north and the lowest in the south (Mercado-Santana et al. 2017).

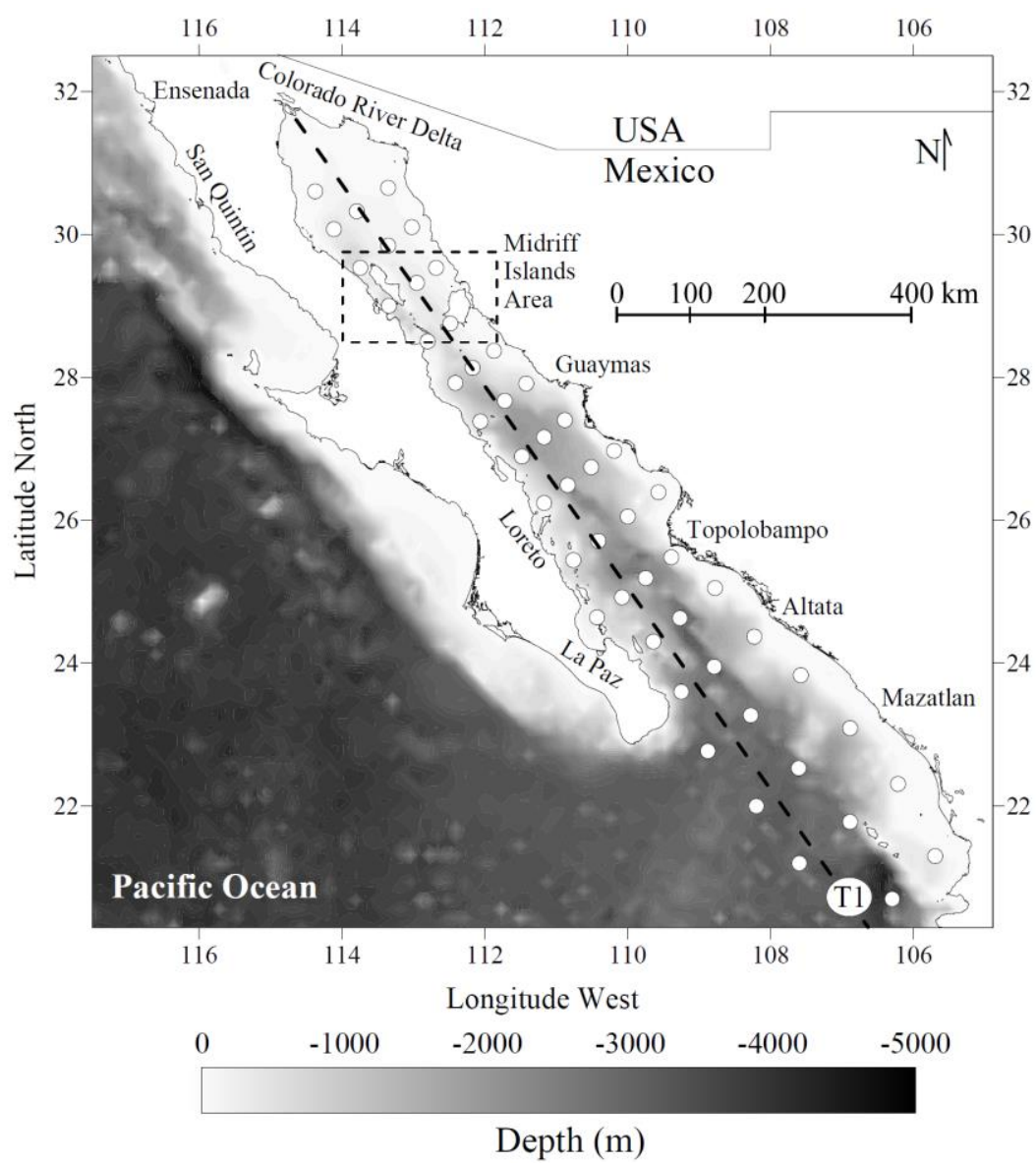

Fig. 1. Gulf of California bathymetry $(\mathrm{m})$. White circles represent the locations of the 50 stations. The dashed line indicates the $1000 \mathrm{~km}$ transect (T1).

Three SST images were acquired from the MODIS-Aqua sensor, dated March 2, 2018, at different initial spatial resolutions $(9 \mathrm{~km}, 4.5 \mathrm{~km}$, and $1 \mathrm{~km})$ from the NASA OceanColor website (https: // oceancolor .gsfc.nasa.gov). Specifically, the MODIS-Aqua images with a spatial resolution of $9 \mathrm{~km}$ and $4.5 \mathrm{~km}$ were downloaded at level 3 through an equidistant cylindrical projection; while the image with a spatial resolution of $1 \mathrm{~km}$ was downloaded at level 2 and geographically projected at level 3 through the SeaDAS-NASA v7.5.1 program. The three images were geographically delimited from $20.5^{\circ}$ to $32^{\circ}$ north latitude and from $105^{\circ}$ to $117.5^{\circ}$ west longitude. We are aware that the three products come from the same data set, but it is irrelevant if we tested the three products separately with the downscale algorithm. Specifically, the three end products via the SeaDAS software are completely different regarding their spatial resolution and projection. The open-source algorithm will work and test these three end products 
separately and once the downscale process is completed, each result will not have a direct relationship with the original set of data regardless of their spatial resolution.

SST level 3 products consist of cumulative data from all level 2 products collected within 24 hours during daytime and nighttime overpasses using the SST4 algorithm. In essence, all SST level 3 products come from level 2 data regardless of the spatial resolution at which they were projected at level 3. It was decided to use a single day to obtain specific fluctuations in SST and thus reduce the inherent smoothing when averaging series of daily images (e.g., every 8 days or monthly). Starting with level 3 products, it is intended to replicate the images in a downscale to determine if the spatial patterns are consistent and thus make the necessary SST comparisons at a much larger scale.

The three SST MODIS-Aqua images were imported into the open-source program in R along with the ncdf4 and raster libraries. The disaggregate command was used with a unique disaggregation factor for each level of processing. For example, matrix $\mathrm{M}_{1}$ represents four SST pixels at an initial spatial resolution of $9 \mathrm{~km}$ :

$M_{1}=\left[\begin{array}{cl}T S M_{i, j} & T S M_{i+1, j} \\ T S M_{i, j+1} & T S M_{i+1, j+1}\end{array}\right]$

Where $i$ and $j$ represent the latitude and longitude positions of the four pixels.

Initially, matrix $\mathrm{M}_{1}$ is downscaled to a first level of processing at $4.5 \mathrm{~km}$ per pixel in two stages, first, we downscale along the horizontal axis (i.e., longitude), followed by downscaling between the above intermediate values but along the vertical axis (i.e., latitude) by means of the following equations:

$U_{\alpha 0}=[1-\alpha] U_{\mathrm{i}, \mathrm{j}}+\alpha\left[U_{\mathrm{i}+1, \mathrm{j}}\right]$

$U_{\alpha 1}=[1-\alpha] U_{\mathrm{i}, \mathrm{j}+1}+\alpha\left[U_{\mathrm{i}+1, \mathrm{j}+1}\right]$

$\operatorname{TSM}_{\mathrm{x}, \mathrm{y}}=[1-\beta] U_{\alpha 0}+\beta\left[U_{\alpha 1}\right]$

Where $\alpha$ and $\beta$ represent the increase in longitude and latitude respectively; $U_{i, j}$ is the previous SST value located at higher latitude; $\mathrm{U}_{\mathrm{i}+1, \mathrm{j}}$ is the posterior SST value at an upper latitude; $\mathrm{U}_{\mathrm{i}, \mathrm{j}+1}$ is the previous SST value at a lower latitude; $\mathrm{U}_{\mathrm{i}+1, \mathrm{j}+1}$ is the posterior value at a lower latitude, and $\mathrm{TSM}_{\mathrm{x}, \mathrm{y}}$ represents the SST downscaled value with $\mathrm{x}, \mathrm{y}$ coordinates.

The two previous stages produce a global scale reduction of the values of the matrix $\mathrm{M}_{1}(9 \mathrm{~km}$ per pixel) to a new matrix $\mathrm{M}_{2}$ of $4.5 \mathrm{~km}$ per pixel:

$M_{2}=\left[\begin{array}{cccc}S S T_{i, j} & S S T_{i+0.25, j} & \multicolumn{1}{c}{S S T_{i+0.75, j}} & S S T_{i+1, j} \\ S S T_{i, j+0.25} & S S T_{i+0.25, j+0.25} & S S T_{i+0.75, j+0.25} & S S T_{i+1, j+0.25} \\ S S T_{i, j+0.75} & S S T_{i+0.25, j+0.75} & S S T_{i+0.75, j+0.75} & S S T_{i+1, j+0.75} \\ S S T_{i, j+1} & S S T_{i+0.25, j+1} & S S T_{i+0.75, j+1} & S S T_{i+1, j+1}\end{array}\right]$

The $9 \mathrm{~km}$ spatial resolution matrix was subsequently reduced to new data sets with spatial resolutions of $4.5 \mathrm{~km}, 1 \mathrm{~km}, 500 \mathrm{~m}, 250 \mathrm{~m}$, and $125 \mathrm{~m}$. Similarly, SST data with a spatial 
resolution of $4.5 \mathrm{~km}$ were reduced to data sets with spatial resolutions of $1 \mathrm{~km}, 500 \mathrm{~m}, 250 \mathrm{~m}$, and $125 \mathrm{~m}$. Finally, the SST data with a spatial resolution of $1 \mathrm{~km}$ were reduced to matrices with spatial resolutions of $500 \mathrm{~m}, 250 \mathrm{~m}$, and $125 \mathrm{~m}$ (Fig. 2).

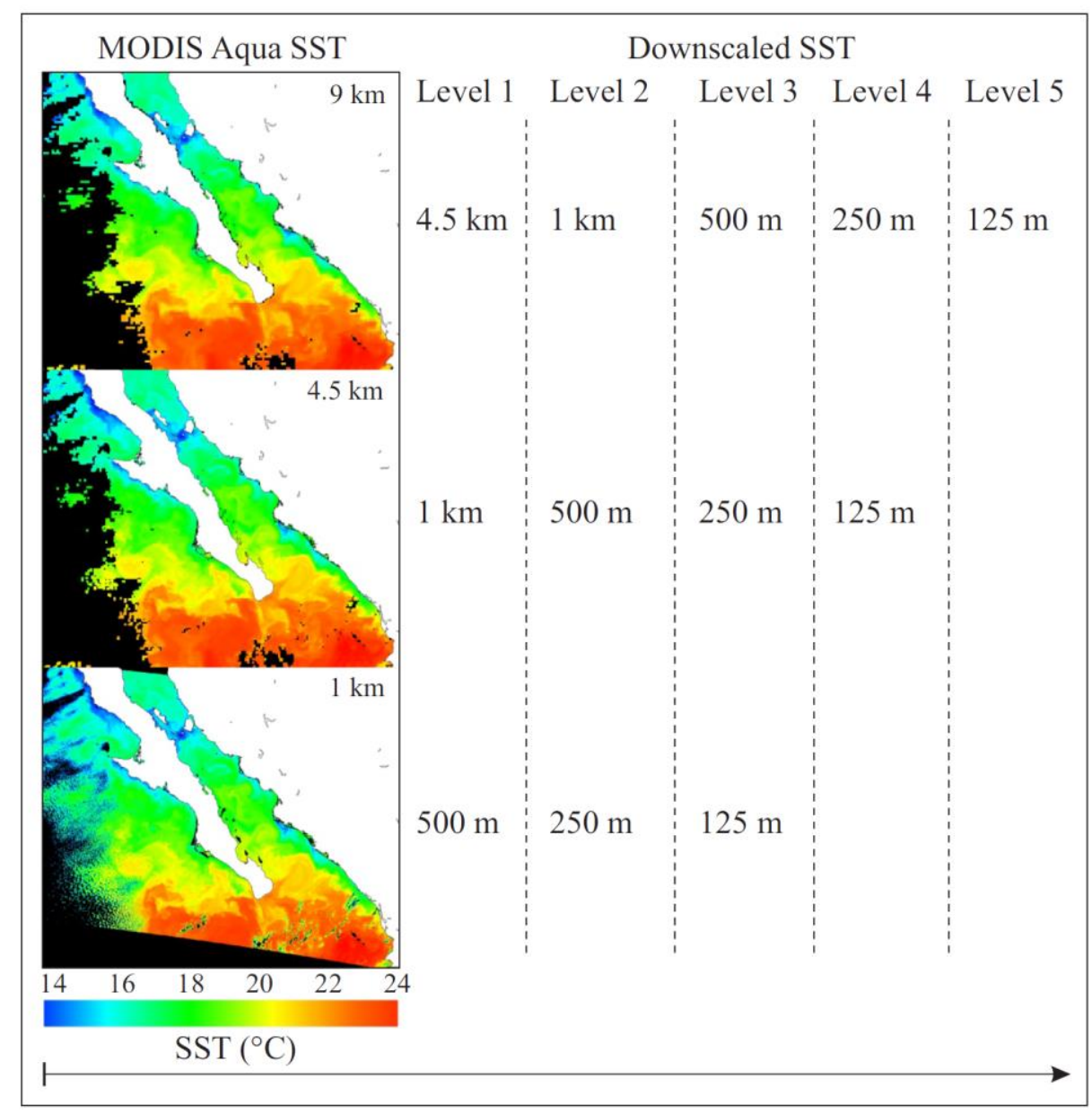

Fig. 2. Flowchart diagram of the downscaled analysis with MODIS-Aqua data through an opensource approach.

To quantitatively compare each data set, we extracted SST values in 1-by-1 and 3-by-3-pixel sampling areas across 50 randomized stations throughout the GC. Subsequently, the mean SST value within each sampling area was calculated (Loisel et al. 2013), additionally we extracted the SST data along a $1000 \mathrm{~km}$ longitudinal transect throughout the GC. Finally, a visual inspection of the SST spatial pattern within the Midriff Islands area was performed with both the original MODIS images as well as the downscaled images. We selected this area due to the strong SST gradient that exists due to intense tidal mixing ( $\sim 5 \mathrm{~m}$ amplitude).

We used the coefficient of determination $\left(\mathrm{R}^{2}\right)$ and the F-test of analysis of variance (ANOVA), to examine the linear association between the downscaled SST values and the original MODISAqua data sets. Linear analysis was performed using SST data extracted from 1-by-1 and 3-by-3pixel sampling areas. 


\section{Results}

Fig. 3 shows the results of the linear regression between the original MODIS sensor SST values and the downscaled SST data with 1-by-1 and 3-by-3-pixel sampling areas. Specifically, the 4.5 $\mathrm{km}$ SST MODIS image was compared to the $4.5 \mathrm{~km}$ downscaled image from the $9 \mathrm{~km}$ MODIS data. Likewise, the $1 \mathrm{~km}$ MODIS image was compared to the $1 \mathrm{~km}$ downscaled image from the MODIS data at $9 \mathrm{~km}$ and $4.5 \mathrm{~km}$, respectively. The results indicate that all the linear associations showed a robust coefficient of determinations, regardless of the sampling area used to extract the data. Hence, the results from the open-source algorithm suggested a feasible downscaling process.
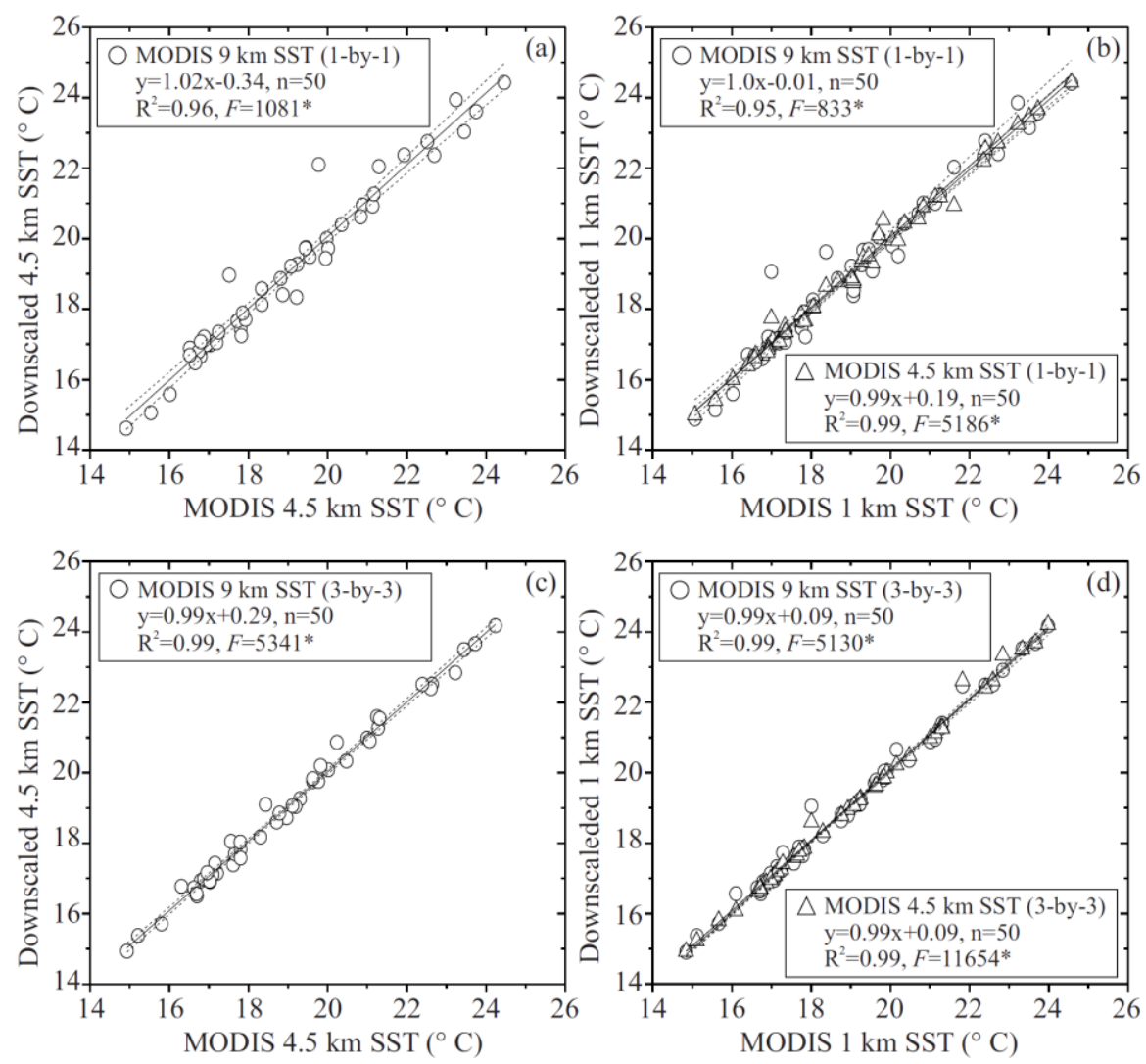

Fig. 3. Linear regressions between MODIS Sea surface temperature (SST) and downscaled SST based on an open-source algorithm. (a) MODIS $4 \mathrm{~km}$ data versus downscaled $4.5 \mathrm{~km}$ data from the MODIS $9 \mathrm{~km}$ data (1-by-1 pixel size). (b) MODIS $1 \mathrm{~km}$ data versus downscaled $1 \mathrm{~km}$ data from the MODIS $9 \mathrm{~km}$ and $4.5 \mathrm{~km}$ data (1-by-1 pixel size). (c) MODIS $4.5 \mathrm{~km}$ data versus downscaled $4.5 \mathrm{~km}$ data from the MODIS $9 \mathrm{~km}$ data (3-by-3-pixel size). (d) MODIS $1 \mathrm{~km}$ data versus downscaled $1 \mathrm{~km}$ data from the MODIS $9 \mathrm{~km}$ and $4.5 \mathrm{~km}$ data (3-by-3-pixel size). Asterisks indicate significant $F$ values at $\alpha=0.05$.

Fig. 4 shows SST MODIS and downscaled SST values along the $1000 \mathrm{~km}$ transect in the GC. In general, all the downscaled values showed a similar trend compared to the original MODIS data. As expected, the profile measured at $9 \mathrm{~km}$ per pixel showed a less detailed pattern compared to the downscaled data, and the lowest SST values were located within the Midriff Islands area. Fig. 5 illustrates examples between the three MODIS images and their respective downscaling in 
the Midriff Islands area. As mentioned above, we selected this specific location because it has the highest SST variability recorded in the entire CG (Martínez-Díaz-de-León et al. 2006). We did not show results below the spatial resolution of $250 \mathrm{~m}$ per pixel because it was not possible to visually distinguish differences. After all, the pixels at that resolution were small and not worth showing because the pattern remained the same. In general, greater detail is seen within downscaled images compared to original MODIS data. The spatial pattern of the MODIS image at $1 \mathrm{~km}$ per pixel fits quite well with the image downscaled to $1 \mathrm{~km}$ per pixel from the MODIS image at $9 \mathrm{~km}$ and $4.5 \mathrm{~km}$, so it was possible to match the SST spatial pattern with the opensource algorithm even up to a processing level of $125 \mathrm{~m}$ per pixel.

\section{Discussion}

The open-source algorithm analyzed in this study was an attempt to develop a comprehensive estimation of SST based on three data sources with different spatial resolutions (i.e., $9 \mathrm{~km}, 4.5$ $\mathrm{km}$, and $1 \mathrm{~km}$ ) from the same MODIS-Aqua sensor. We already explained the limitations of the single data source from level 2 in the methods section, but we believe that our approach should not be affected by this potential limitation because the three final data sets were downscaled separately by the open-source algorithm.

The proposed modeling approach of integrating an extraction with 1-by-1 and 3-by-3-pixel sampling areas provided a simulated SST derivation technique for all 50 sampling stations. This is a common approach in a situation where a strong SST gradient is present such as the GC (Escalante et al. 2013). Overall, this study presents a spatial downscaling approach to transfer data with lower spatial resolution into an SST matrix with finer spatial resolution without using commercial or black-box software. Hence, the present work demonstrates the feasibility of the open-source algorithm to project SST data on a much larger scale without losing the overall trend in the spatial distribution pattern.

Currently, several techniques have been developed to downscale data and they have been evaluated mainly individually without comparing them with each other (Celant and Broniatowski 2016). Therefore, scarce studies have focused on quantifying the accuracy among data sets with a different spatial resolution (Li and Heap 2008). In this sense, downscaling techniques represent a substantial challenge, and therefore the ability of downscaling methods is based on a clear link between the nature of spatial variation and the sampling efficiency (Atkinson 2005).

Consequently, the results of the linear trend between the SST MODIS data at $4.5 \mathrm{~km}$ and $1 \mathrm{~km}$ together with the data reduced to $4.5 \mathrm{~km}$ and $1 \mathrm{~km}$, coming from different initial spatial resolution, revealed minimal differences in the modeling of SST using different sampling areas (1-by-1 and 3-by-3-pixels). Furthermore, a visual comparison, as suggested by Xu et al. (2014), between the downscaled images (Fig. 5), indicates that the proposed approach was successful in replicating the SST spatial pattern. 

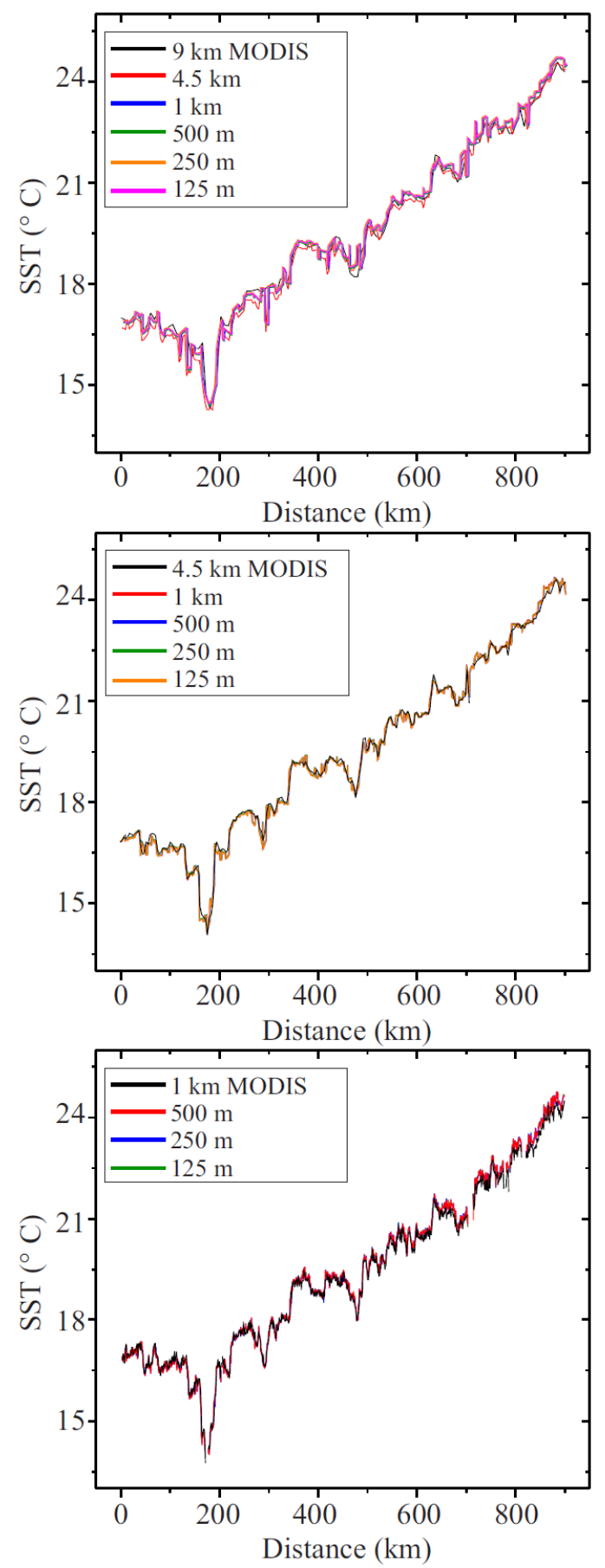

Fig. 4. Downscaled sea surface temperature (SST) along the $1000 \mathrm{~km}$ transects (T1) based on a sampling area extraction of 1-by-1 pixel size. From top to bottom, downscaled $4.5 \mathrm{~km}, 1 \mathrm{~km}, 500$ $\mathrm{m}, 250 \mathrm{~m}$, and $125 \mathrm{~m}$ SST data based on the MODIS $9 \mathrm{~km}$ per pixel data. Downscaled $1 \mathrm{~km}, 500$ $\mathrm{m}, 250 \mathrm{~m}$, and $125 \mathrm{~m} \mathrm{SST}$ data based on the MODIS $4 \mathrm{~km}$ per pixel data. Downscaled $500 \mathrm{~m}$, $250 \mathrm{~m}$, and $125 \mathrm{~m}$ SST data based on the MODIS $1 \mathrm{~km}$ per pixel SST data. 

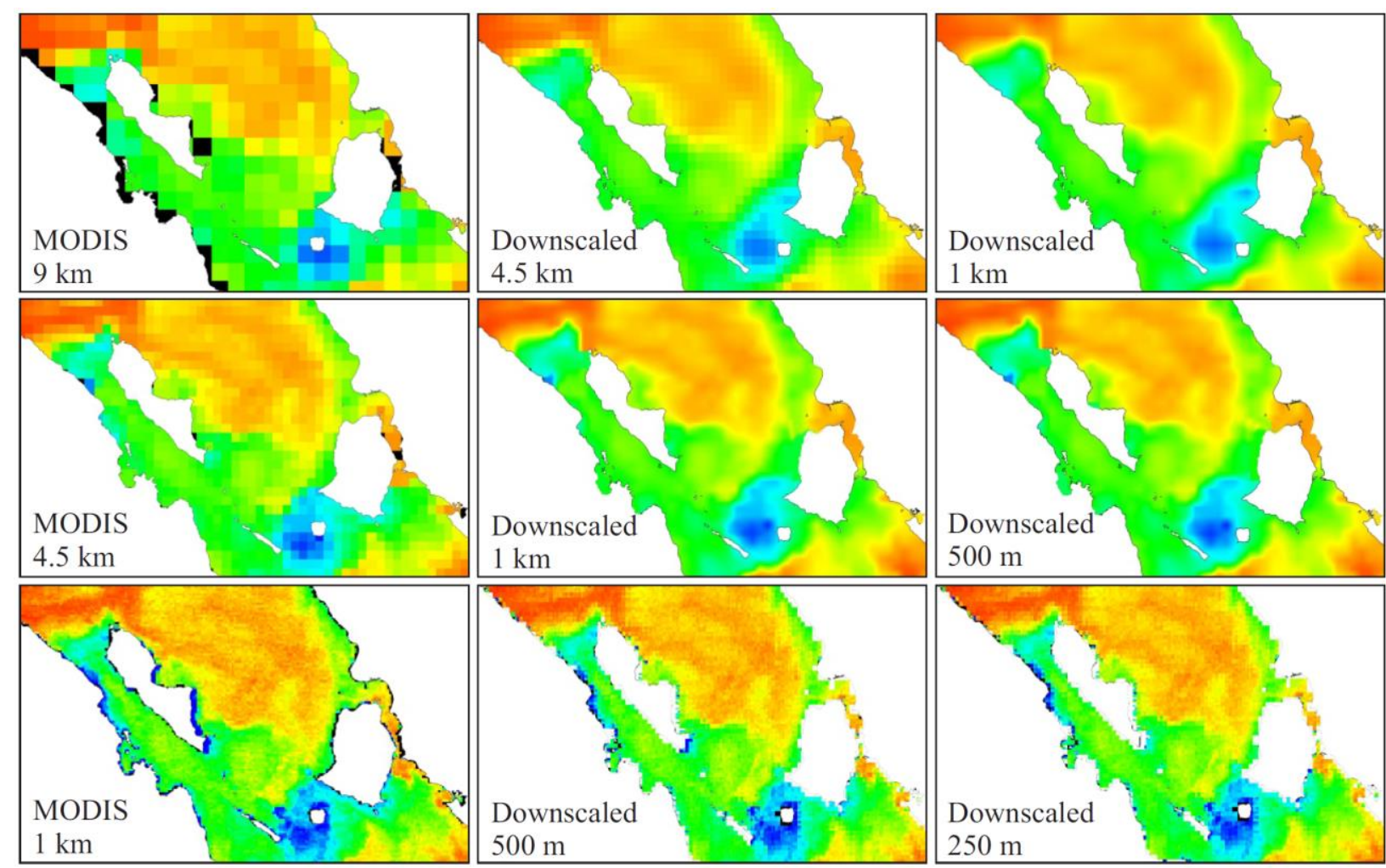

14

15

16

17 18

$\operatorname{SST}\left({ }^{\circ} \mathrm{C}\right)$

Fig. 5. Spatial distribution of downscaled sea surface temperature (SST) at the Midriff Islands area based on three data sources from the MODIS-Aqua $(9 \mathrm{~km}, 4.5 \mathrm{~km}$, and $1 \mathrm{~km})$. From left to right, original MODIS data and their respective downscaled images.

The results of the linear analysis revealed a similarity between the MODIS data and the downscaled data, regardless of their spatial resolution and the size of the sampling area. This situation was supported by the SST pattern extracted from the longitudinal transect throughout the entire GC. It has been suggested that clustering of data could affect the estimated accuracy, and the effects may also depend on the selected downscale algorithm (Li and Heap, 2008). In this sense, a strong spatial gradient, such as the SST recorded throughout the CG, usually increases the coefficient of determination between the measured and estimated values regardless of the method used (Atkinson 2005). Furthermore, the spatial distribution of the data could also affect the performance of the spatial reduction method ( $\mathrm{Li}$ and Heap, 2008). For example, the opensource downscaling algorithm used in this study worked very well in this marginal sea, probably because of the aforementioned SST gradients.

It is important to consider the computational efficiency of downscaling methods, especially in real-time applications (Wang et al. 2014). Although all SST values replicated the spatial pattern of the initial MODIS data, the downscale images presented more detail and, consequently, the files took a considerable amount of time to create, especially where there was a considerable increase in detail (e.g., $500 \mathrm{~m}, 250 \mathrm{~m}$, and $125 \mathrm{~m}$ from the $9 \mathrm{~km}$ MODIS image). The data 
density of the extracted 3-by-3-pixel sampling area presented a substantial challenge for the downscaling of SST because a much larger area was extracted per pixel. Although it was possible to obtain a similar spatial pattern among the images, it is important to recognize the main limitations of our study. For example, it should be noted that the spatial accuracy of downscaled algorithms depends on several factors, such as the original spatial resolution scale (Suresh and Jain 2018). In this sense, the algorithm that uses a 1-by-1 pixel sampling area extraction considers the four neighboring pixels regardless of their initial spatial resolution. Furthermore, MODIS-Aqua images acquired in different periods (e.g., days, months, or years) can be expected to exhibit different spectral characteristics, even when the scene has not changed, due to atmospheric variabilities such as cloud cover, environmental temperature, and the conditions of the angle of the Sun over time (Zhang et al. 2017). Another relevant factor is data density, which plays a relevant role in the performance of spatial downscale methods (Li and Heap 2008). For example, the underlying assumption about the variation among neighboring pixels may differ in the absence of many continuous data, and the downscale algorithm could increase the missing values (Celant and Broniatowski 2016). However, in our study area, it was possible to replicate the spatial pattern even along with coastal areas where there were no recorded values, as seen in Fig. 5.

The proposed open-source downscaling method for estimating SST could be important in providing quick and relevant information on SST variability along small sections of the coastline. Indeed, it is often difficult to make predictions of coastal variables with remote sensing data, and coastal populations are increasingly prone to extreme events, such as flooding from tropical storms and hurricanes, increasing agricultural and river discharge flows (Dogliotti et al. al. 2016), and its response in optical variables such as chlorophyll-a concentration (MercadoSantana et al. 2017). In this sense, our approach could be used to assess river plume dynamics in areas where data with the coarse spatial resolution is commonly used. Finally, using an opensource program provides us with the necessary tools to analyze data regardless of the geographical area or the need to invest in software that requires a commercial license.

\section{Conclusions}

Both the quantitative and visual evaluations showed the feasibility of the open-source algorithm in reconstructing a single SST image across coastal and oceanic regions, such as the GC. However, the downscaled SST matrix for each level depends on the original spatial resolution within each image. Although the three original MODIS-Aqua data sets come from the same processing level, we believe that this possible limitation was not relevant because the opensource algorithm processed the three matrices separately. Moreover, the original spatial material within the three matrices was completely different among them, and thus the open-source algorithm processed each matrix with their corresponding spatial resolution. Additional research is needed to evaluate our findings at other representative sites with different oceanographic dynamics from those found in the GC. In this sense, more work is required to evaluate the performance of other downscaling algorithms within the results found in this study. 


\section{Acknowledgments}

This work was supported by the Instituto de Ciencias del Mar y Limnología (UNAM), Mexico under grant number 622 .

\section{References}

Atkinson PM. 2005. Sub-pixel target mapping from soft-classified, remotely sensed imagery. Photogramm Eng Remote Sens. 7: 839-846.

Barale V, Gower JFR, Alberotanza L. 2010. Oceanography from space: revisited. Netherlands: Springer.

Callejas-Jimenez M, Santamaria-del-Angel E, Gonzalez-Silvera A, Millan-Nuñez R, CajalMedrano R. 2012. Dynamic regionalization of the Gulf of Mexico based on normalized radiances (nLw) derived from MODIS-Aqua. Cont Shelf Res. 37: 8-14.

Carrasco AR, Ferreira O, Roelvink D. 2016. Coastal lagoons and rising sea level: A review. Earth-Sci Rev. 154: 356-368.

Celant G. Broniatowski M. 2016. Interpolation and extrapolation optimal designs V1: polynomial regression and approximation theory. New Jersey (NJ): John Wiley \& Sons.

Contreras-Catala F, Sánchez-Velasco L, Beier E, Godínez VM, Barton ED, Santamaría-delAngel E. 2016. Effects of geostrophic kinetic energy on the distribution of mesopelagic fish larvae in the Southern Gulf of California in summer/fall stratified seasons. PLoS One. 11(10): e0164900.

Devi GK, Ganasri BP, Dwarakish GS. 2015. Applications of remote sensing in satellite oceanography: A review. Aquat Procedia. 4: 579-584.

Dogliotti AI, Ruddick K, Guerrero R. 2016. Seasonal and inter-annual turbidity in the Río de la Plata from 15 years of MODIS: El Niño dilution effect. Estuarine Coastal Shelf Sci. 182: 27-39.

Escalante F, Valdez-Holguín JE, Álvarez-Borrego S, Lara-Lara JR. 2013. Temporal and spatial variation of sea surface temperature, chlorophyll a, and primary productivity in the Gulf of California. Cienc Mar. 39(2): 203-215.

Espinosa-Carreón TL, Escobedo-Urías D. 2017. South region of the Gulf of California large marine ecosystem upwelling fluxes of $\mathrm{CO}_{2}$ and nutrients. Environ Dev. 22: 42-51.

Fablet R, Viet PH, Lguensat R, Horrein PH, Chapron B. 2018. Spatio-temporal interpolation of cloudy SST fields using conditional analog data assimilation. Remote Sens. 10: 310. 
Gonzalez-Silvera A, Santamaria-del-Angel E, Millán-Núñez R. 2006. Spatial and temporal variability of the Brazil-Malvinas confluence and the La Plata plume as seen by SeaWiFS and AVHRR imagery. J Geophys Res. 111: C06010.

Gonzalez-Silvera A, Santamaria-del-Angel E, Millán-Nuñez R, Manzo-Monroy H. 2004. Satellite observations of mesoscale eddies in the Gulf of Tehuantepec and Papagayo (Eastern Tropical Pacific). Deep Sea Res II. 51: 587-600.

Jensen JR. 2006. Remote sensing of the environment: an earth resource perspective. New Jersey (NJ): Prentice Hall.

Knutson TR, McBride JL, Chan J, Emanuel K, Holland G, Landsea C, Held I, Kossin JP, Srivastava AK, Sugi M. 2010. Tropical cyclones and climate change. Nat Geosci. 3: 157-163.

Kratzer S, Alikas K, Harvey T, Beltrán-Abaunza JM, Morozov E, Mustapha SB, Lavender S. 2016. Multitemporal remote sensing of coastal waters. Remote Sens Digital Image Process. 20: 391-426.

Li J, Heap AD. 2008. A review of spatial interpolation methods for environmental scientists. Canberra: Geoscience Australia Record.

Ling F, Du Y, Li X, Li W, Xiao F, Zhang Y. 2013. Interpolation-based super-resolution land cover mapping. Remote Sens Lett. 4(7): 629-638.

Loisel H, Vantrepotte V, Jamet C, Ngoc D. 2013. Challenges and new advances in ocean color remote sensing of coastal waters. In: Zambianchi E, editor. Topics in Oceanography. London: InTech: p. 1-38.

Mercado-Santana JA, Santamaría-del-Ángel E, González-Silvera A, Sánchez-Velasco L, GraciaEscobar MF, Millán-Núñez R, Torres-Navarrete C. 2017. Productivity in the Gulf of California large marine ecosystem. Environ Dev. 22: 18-29.

Mokarrama M, Hojati M. 2018. Landform classification using a sub-pixel spatial attraction model to increase spatial resolution of digital elevation model (DEM). Egypt J Remote Sens Space Sci. 21: 111-120.

Nielsen-Englyst P, Høyer JL, Pedersen LT, Gentemann CL, Alerskans E, Block T, Donlon C. 2018. Optimal estimation of sea surface temperature from AMSR-E. Remote Sens. 10: 229.

Platt T, Sathyendranath S. 2008. Ecological indicators for the pelagic zone of the ocean from remote sensing. Remote Sens Environ. 112: 3426-3436.

Suresh M, Jain K. 2018. Subpixel level mapping of remotely sensed image using colorimetry. Egypt J Remote Sens Space Sci. 21: 65-72. 
Wang Q, Shi W. 2014. Utilizing multiple subpixel shifted images in subpixel mapping with image interpolation. IEEE Geosci Remote Sens Lett. 11(4): 798-802.

Wang Q, Shi W, Atkinson PM. 2014. Sub-pixel mapping of remote sensing images based on radial basis function interpolation. ISPRS J Photogramm Remote Sens, 92: 1-15.

Xu X, Zhong Y, Zhang L. 2014. A sub-pixel mapping method based on an attraction model for multiple shifted remotely sensed images. Neurocomputing. 134: 79-91.

Zhang Y, Atkinson PM, Li X, Ling F, Wang Q, Du Y. 2017. Learning-based spatial-temporal superresolution mapping of forest cover with MODIS images. IEEE Trans Geosci Remote Sens. 55(1): 600-614. 